\title{
Relocating ruptures of two $M 6$ earthquakes in Zhongba, South-central Tibet in 2004 and 2005 with seismological and geodetic methods*
}

\author{
Feng Bao Yingjie Zha Zhenjie Wang* \\ Mengcheng National Geophysical Observatory, School of Earth and Space Sciences, University \\ of Science and Technology of China, Hefei 230026, China
}

\begin{abstract}
To better understand repeatability of strong earthquakes in previously ruptured zones during one seismogenic period, we studied the rupture zones of the doublet of $M 6$ earthquakes in Zhongba region of southcentral Tibet, China, in 11 July 2004 and 7 April 2005, respectively. We focused on the overlapping degree of two strong quakes' aftershock areas one week after the mainshocks by using the SQH station in China Seismic Network and a 68-stations temporary broadband seismic array, a part of the international HI-CLIMB project. About 115 local earthquakes were recorded in one week after the mainquakes, and we located these earthquakes by master event relative location (MERL) method. We also used this method to relocate 31 other $M 3.7^{+}$earthquakes from 1 July 2004 to 1 July 2005. Meanwhile, we studied two mainshocks' coseismic ruptures with satellite interferometric synthetic aperture radar (InSAR). Our results show that the ruptured zones of the two earthquakes do not overlapp substantially, either from early aftershock data or from InSAR inversions.
\end{abstract}

Key words: rupture zone overlapping; Zhongba earthquake sequences; earthquake doublets; master event relative location; InSAR

CLC number: P315.3 Document code: A

\section{Introduction}

Rupture zone generated by a mainshock generally features a linear and limited distribution in releasing stress after brittle fracture of what happened underground (Waldhauser and Ellsworth, 2000). Many parameters used to describe the nature of rupture zone structure such as location, area, rupture length and width, can be observed in the surface sometimes (Xu et al., 2008). However, most damaging normal fault earthquakes are buried deep into the Earth and have little surface rupture. To better understand the fault geometry associated with these earthquakes and assess local seismic hazard as well as gaining a better

\footnotetext{
* Received 16 December 2010; accepted in revised form 18 March 2011; published 10 April 2011.

† Corresponding author. e-mail: wzjwzj@mail.ustc.edu.cn

(c) The Seismological Society of China and Springer-Verlag Berlin Heidelberg 2011
}

understanding of rupture process, some methods have been used, such as simulating rupture process by using finite-fault model simulation (Somerville et al., 1991; Li et al., 2005), determining aftershock zones by using high-precision aftershock location, and defining the fault geometry and slip distribution by using modern InSAR processing (Massonnet et al., 1994; $\mathrm{Xu}$ and $\mathrm{Li}$, 2008).

Whether another strong earthquake could take place in previous rupture zones, or two mainshocks' rupture zones could overlap with each other substantially during the same seismogenic time remains a puzzle and has attracted many seismologists' attention. Structural features such as faults, trenches, and ridges, can separate adjacent ruptures, which have been observed in Japan (Mogi, 1969) and Aleutian Islands (Kelleher, 1970; Sykes, 1971). Consequently, it is suggested that barriers caused by fault geometry such as bends, steps, corners (Segall and Pollard, 1980), or crustal inhomo- 
geneities inferred from velocity anomalies, delimit two earthquake rupture zones and are regard as acting as stress concentrators (Aki, 1979).

One method to obtain rupture dimensions and correlations of earthquakes' rupture zones is to analyze aftershocks' distribution and it is discovered that aftershock areas of larger earthquakes tend to fill up a seismic zone without significant overlap (Aki, 1978). Similarly, great $\left(M_{\mathrm{S}} \geq 7.5\right)$ and shallow earthquakes in the Kamchatka, Kurile and Japan regions rupture and split to discrete fault segments, which were defined as aftershock zones (Fedotov, 1965).

The main purpose of this paper is to obtain the aftershock areas of Zhongba earthquake doublets, which occurred in 11 July 2004 and 7 April 2005, respectively. Combining master event relative location (MERL) and Interferometric Synthetic Aperture Radar (InSAR) technology, we discussed the properties of the aftershock areas and overlapping degree of earthquake doublets' rupture zones.

\section{Stations and data}

Most data in our study come from the Himalayan Tibetan Continental Lithosphere during Mountain Building experiment (Hi-CLIMB), an international collaborative project to investigate active mountainbuilding over the entire thickness of the lithospheric structures across the Himalayan-Tibetan zone of continent-continent collision from 2003 to 2005. During the three-year experiment, 115 broadband seismometers were deployed from southern Nepal to the north of the Bang-gong suture in central Tibet (Hetenyi et al., 2008; Nabelek et al., 2009; Wittlinger et al., 2009). The northern section of Hi-CLIMB network consisted of 75 stations, and 68 of these stations were in south-central Tibet (Figure 1). Those stations and the SQH station (a permanent station in China Seismic Network),

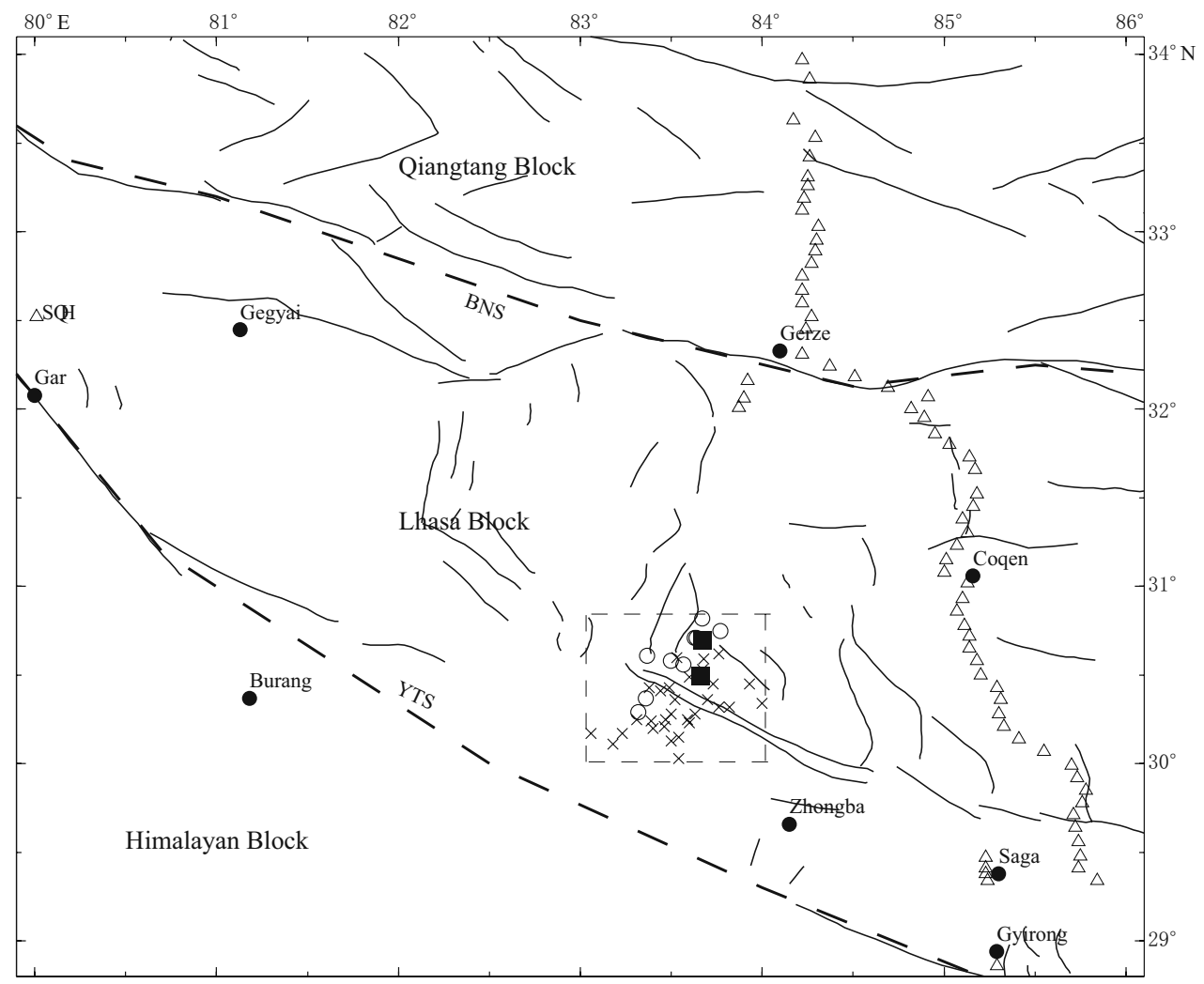

Figure 1 Distribution of stations, regional geological tectonics and preliminary determination epicenter from NEIC. The triangles are stations used in the research area indicated by the dashed rectangle; the circles are preliminary determination epicenters located by USGS from 1 July 2004 to 1 January 2005, and the crosses are preliminary determination epicenters from 1 April 2005 to 1 October 2005. Two squares are earthquake doublets' preliminary determination epicenter from NEIC. The solid dots indicate county towns. Two thick dashed lines implicate BNS (Banggong-Nujiang Suture) and YTS (Yarlung-Tsangpo Suture). The thin solid lines indicate local active faults. 
were used in our study. The seismic station array with a strike of about $\mathrm{N} 345^{\circ} \mathrm{W}$ was deployed from June 2004 to September 2005 and can be divided into two sections from Lhasa block's Gyirong-Saga-Cochen-Gerze to Qiangtang Block roughly. Our study region is between YTS (Yarlung-Tsangpo Suture) and BNS (BanggongNujiang Suture), situated at the northeast of Himalayan block and the south of Qiangtang block.

Two datasets of seismic waveform were selected for this study. One contains data from earthquakes of magnitude greater than 2 in a week after 11 July 2004 and 7 April 2005, respectively, while the other group comprised earthquakes of magnitude greater than 3.7 from 1 July 2004 to 1 July 2005. The two M6 mainshock are very close to each other according to NEIC's catalog, and their aftershocks seem to overlap each other (Figure 1) which may suggest that the two mainshocks ruptured overlapped area. But NEIC's location is typically not accurate within $15 \mathrm{~km}$, therefore the seemingly overlapping could be an artifact, and accurate relocation is necessary to illuminate the issue of whether the aftershock zones overlap.

The aftershocks within one week from the mainshock are chosen as early shocks, which are proposed to present rupture zones of the mainshock. Later shocks may migrate well beyond the main rupture zone (Kisslinger, 1996), but the cut-off span of one week could be a little bit arbitrary. Wan et al. (2009) find that the aftershocks in the first two hours are good enough to delineate rupture zones. The data came from various seismometers' observation such as broadband seismometers Streckeisen STS-2, Guralp CMG-3T with a natural period of $120 \mathrm{~s}$, and intermediate-band seismometers Guralp CMG-3ESP with a natural period of 33 s. To compare results from different instruments, seismograms were corrected by removing instrument response with the pole zero files.

\section{Methods}

Master event relative location (MERL) is a method to determine event position by using a set of P-wave traveltime differences $\left(T_{X j}-T_{R j}\right)$ recorded at $N$ stations for $j=1,2, \cdots, N$, in which $R$ is a reference event and $X$ is a nearby event (Spence, 1980; Zhou et al., 1999; Yang et al., 2002). Given the reference event $R$, of latitude $\varphi_{R}$, longitude $\lambda_{R}$, and focal depth $h_{R}$, closing to a candidate event $X$ with undetermined epicentral location $\left(\varphi_{X}, \lambda_{X}, h_{X}\right)$, an equation for the reference event $R$ 's arrival time at a seismic station $j$ is

$$
t_{R j}=t_{0 R}+T_{j}\left(\varphi_{R}, \lambda_{R}, h_{R}\right)+s_{j} .
$$

Similarly, the equation for the candidate event $X$ 's arrival time at seismic station $j$ is

$$
t_{X j}=t_{0 X}+T_{j}\left(\varphi_{X}, \lambda_{X}, h_{X}\right)+s_{j} .
$$

There are $N$ stations, each of which has been given the coefficient of station correction $s_{j}$. The $t_{j}$ is arrival time of $\mathrm{P}$ wave obtained from waveform, and $t_{0}$ is the origin time. $T_{j}$ represents travel time from the epicenter to the seismic station.

To find a linearization of the equation (2) in the parameter space of the reference event $R$, a Taylor series expansion is formed at $T_{j}\left(\varphi_{R}, \lambda_{R}, h_{R}\right)$.

$$
\begin{gathered}
t_{X j}=t_{0 X}+T_{j}\left(\varphi_{R}+\delta_{\varphi}, \lambda_{R}+\delta_{\lambda}, h_{R}+\delta_{h}\right)+s_{j} \\
=t_{0 X}+T_{j}\left(\varphi_{R}, \lambda_{R}, h_{R}\right)+\frac{\partial T_{j}\left(\varphi_{R}, \lambda_{R}, h_{R}\right)}{\partial \varphi} \delta \varphi+ \\
\\
\frac{\partial T_{j}\left(\varphi_{R}, \lambda_{R}, h_{R}\right)}{\partial \lambda} \delta \lambda+\frac{\partial T_{j}\left(\varphi_{R}, \lambda_{R}, h_{R}\right)}{\partial h} \delta h+s_{j} .
\end{gathered}
$$

Equation (3) minus equation (1), we obtain

$$
\begin{gathered}
\delta t_{\mathrm{j}}=\delta t_{0}+\frac{\partial T_{j}\left(\varphi_{R}, \lambda_{R}, h_{R}\right)}{\partial \varphi} \delta \varphi+ \\
\frac{\partial T_{j}\left(\varphi_{R}, \lambda_{R}, h_{R}\right)}{\partial \lambda} \delta \lambda+\frac{\partial T_{j}\left(\varphi_{R}, \lambda_{R}, h_{R}\right)}{\partial h} \delta h
\end{gathered}
$$

namely,

$$
\delta t_{j}=\delta t_{0}+\delta T_{j}
$$

Arrival time difference $\delta t_{j}$ is available. However, origin time difference $\delta t_{0}$ and the travel time difference $\delta T_{j}$ is unknown.

As it shown in the Figure 2, equation (5) can be indicated as

$$
\delta t_{j}=\delta t_{0}+\frac{\delta x}{v} \sin \alpha+\frac{\delta y}{v} \cos \alpha
$$

The $v$ is the mean velocity of $\mathrm{P}$ wave in the Earth's crust, and the $\alpha$ is reference event $R$ 's azimuth, which is identified with the undetermined event $X$ as two quakes are so close.

\section{Results}

The first mainshock on July 11 2004, was relocated with arrival time data from the SQH station and Hi-CLIMB stations, and then chosen to be the master event of MERL to improve the accuracy of absolute position of earthquake sequences. 


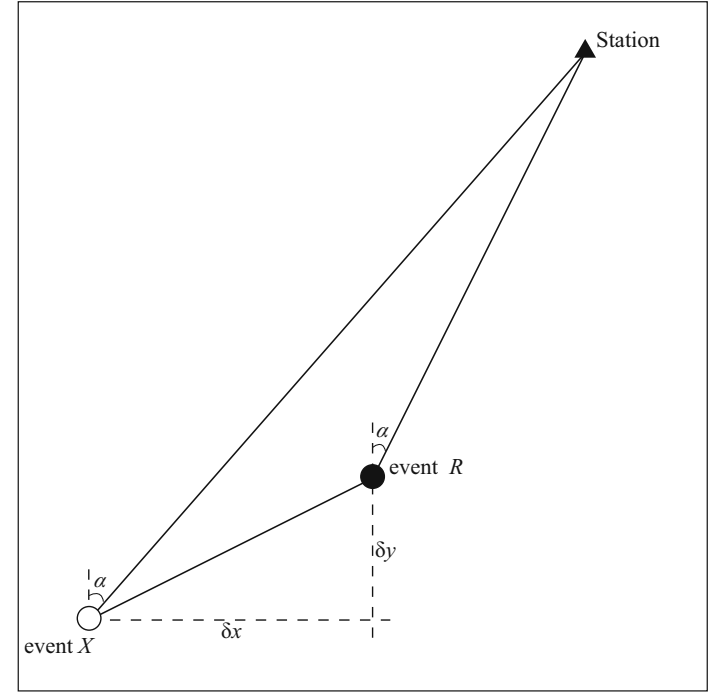

Figure 2 Sketch map of the master event relative location. The triangle is some station, and the circles are master and undetermined events' epicenters. The $\alpha$ is event $R$ 's azimuth, identified with event $X$ 's azimuth.

\subsection{Relocation of master event}

The earthquake location program HYPOINVERSE2000 was adopted to achieve absolute positioning of the master event. In the program, we picked $\mathrm{P}$ wave arrival time from seismic station record in the 68 stations of Hi-CLIMB seismic array and SQH station; also onedimension crustal velocity structure model beneath Lhasa block was introduced. This model came from existing study in the nearby region (Zhao et al., 1991, 2001; Nabelek et al., 2009; Wittlinger et al., 2009) , and we assumed the value of the $\mathrm{P}$ to $\mathrm{S}$ velocity ratio to be 1.73 (Table 1).

Table 1 One-dimensional velocity structure of the crust used in the study

\begin{tabular}{cccc}
\hline Layer & Depth $/ \mathrm{km}$ & $v_{\mathrm{P}} / \mathrm{km} \cdot \mathrm{s}^{-1}$ & $v_{\mathrm{S}} / \mathrm{km} \cdot \mathrm{s}^{-1}$ \\
\hline Upper crust & $0.0-18.0$ & 5.60 & 3.24 \\
Middle crust & $18.0-33.0$ & 6.00 & 3.47 \\
Lower crust & $33.0-65.0$ & 6.50 & 3.76 \\
Upper mantle & $>65.0$ & 8.00 & 4.62 \\
\hline
\end{tabular}

Table 2 shows the difference between our result and USGS, where location difference is about $6 \mathrm{~km}$, better than the typical NEIC accuracy of $15 \mathrm{~km}$. Of course our location may have some error because the azimuthal gap of the stations is fairly large (about $250^{\circ}$; Figure 1 ). We also included $\mathrm{S}$ wave arrival in locating the mainshock, but the difference is small as compared with location with $\mathrm{P}$ wave only. Considering that $\mathrm{S}$ onset picking is not very precise, here we only report location from $\mathrm{P}$ arrivals. Seismic location of the master event was plotted in the Figure 3.

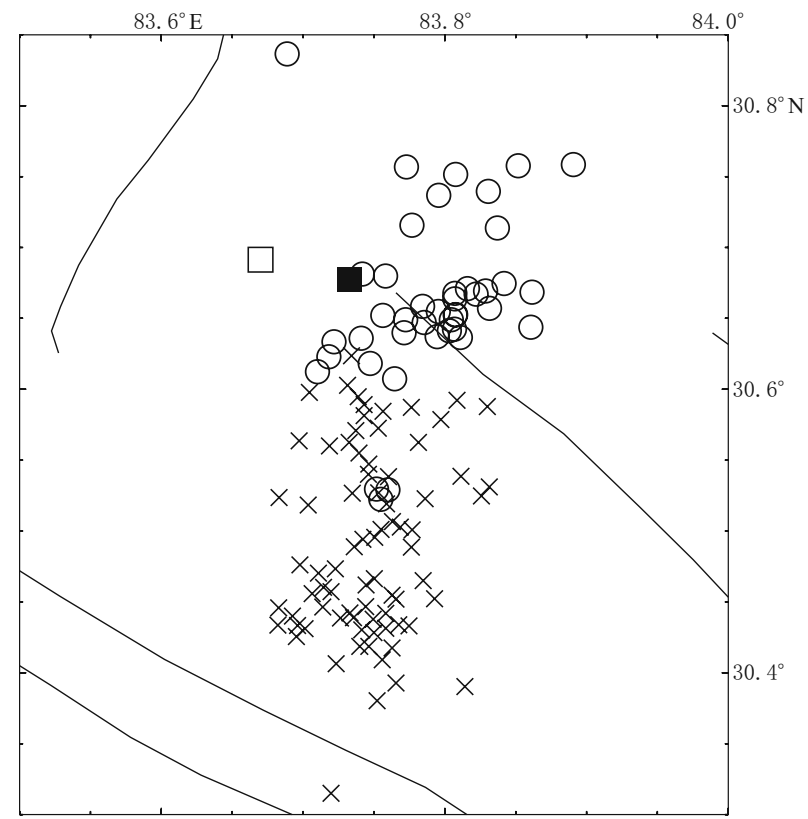

Figure 3 Location of earthquake sequences, including earthquake doublets and their aftershocks within one week after the mainshocks. The solid square is the master event, the first mainshock, relocated by HYPOINVERSE-2000, also located and cataloged by USGS, demonstrating by open square. The circles are the aftershock sequences within a week after the first mainshock, 11 July 2004. And the crosses are the aftershock sequences within a week after the second mainshock, 7 April 2005. The thin lines indicate local active faults.

Table 2 Location of master event, 11 July 2004

\begin{tabular}{ccccccc}
\hline Method & $\begin{array}{c}\text { Date } \\
\text { a-mo-d }\end{array}$ & $\begin{array}{c}\text { Origin time } \\
\text { (UTC) }\end{array}$ & Lat. $/{ }^{\circ} \mathrm{N}$ & Long. $/{ }^{\circ} \mathrm{E}$ & Depth $/ \mathrm{km}$ & $M$ \\
\hline USGS & $2004-07-11$ & $23: 08: 44.18$ & 30.69 & 83.67 & 13 & 6.2 \\
MERL & $2004-07-11$ & $23: 08: 42.19$ & 30.68 & 83.73 & 8 & $6.15^{*}$ \\
\hline
\end{tabular}

Note: The number with $*$ is achieved by the method of cut and paste (CAP). 


\subsection{Accurate location of undetermined event}

The accuracy of absolute epicentral location is limited by the knowledge of the crustal structure and one-dimensional velocity model is not sufficient to obtain very accurate absolute location. However, errors in structure can be effectively minimized by using relative location methods, such as MERL (Spence, 1980).

Considering that aftershock zones may expand both horizontally and vertically, aftershock zones within a week after the mainquake are more suited to represent the range of co-seismic rupture zone than that within several months (Henry and Das, 2001; Kisslinger, 1996). In our study region, 115 local earthquake sequences of magnitude greater than 2 , including the two mainshock and earthquake doublets' aftershocks recorded within one week after the mainquakes, were located via MERL using data from 68 stations of Hi-CLIMB seismic array. The onset of the seismic data was picked from $\mathrm{P}$ waveforms. As shown in Figure 3, the epicenter of earthquake doublets sequences are divided into two parts and presents a linear and limited distribution with $60 \mathrm{~km}$ long in SN direction. The length of north aftershock zone is about $27 \mathrm{~km}$, and the width is about $22 \mathrm{~km}$. However, the length of south aftershock zone is about $39 \mathrm{~km}$, and the width is about $14 \mathrm{~km}$. The second co-seismic rupture zone is slenderer than the first one, the master event's rupture area. We also note that three events, happened in 12 July 2004, of the first earthquake sequence have shocked inside the second rupture zone, and are much close to the second mainshock. As these three events occurred on the second day after the first mainshock and next to the second mainshock, we supposed that they may have had a role in triggering the second mainshock. Of course, this supposition needs further research to prove to be true.

However, seismological methods usually do not provide ground truth location for earthquakes. In contrast, InSAR data can provide very accurate ground truth locations (Saikia et al., 2003). Therefore, we also modeled these two mainshocks with INSAR data. The co-seismic deformation field in the line of sight (LOS) associated with these two mainshocks was obtained

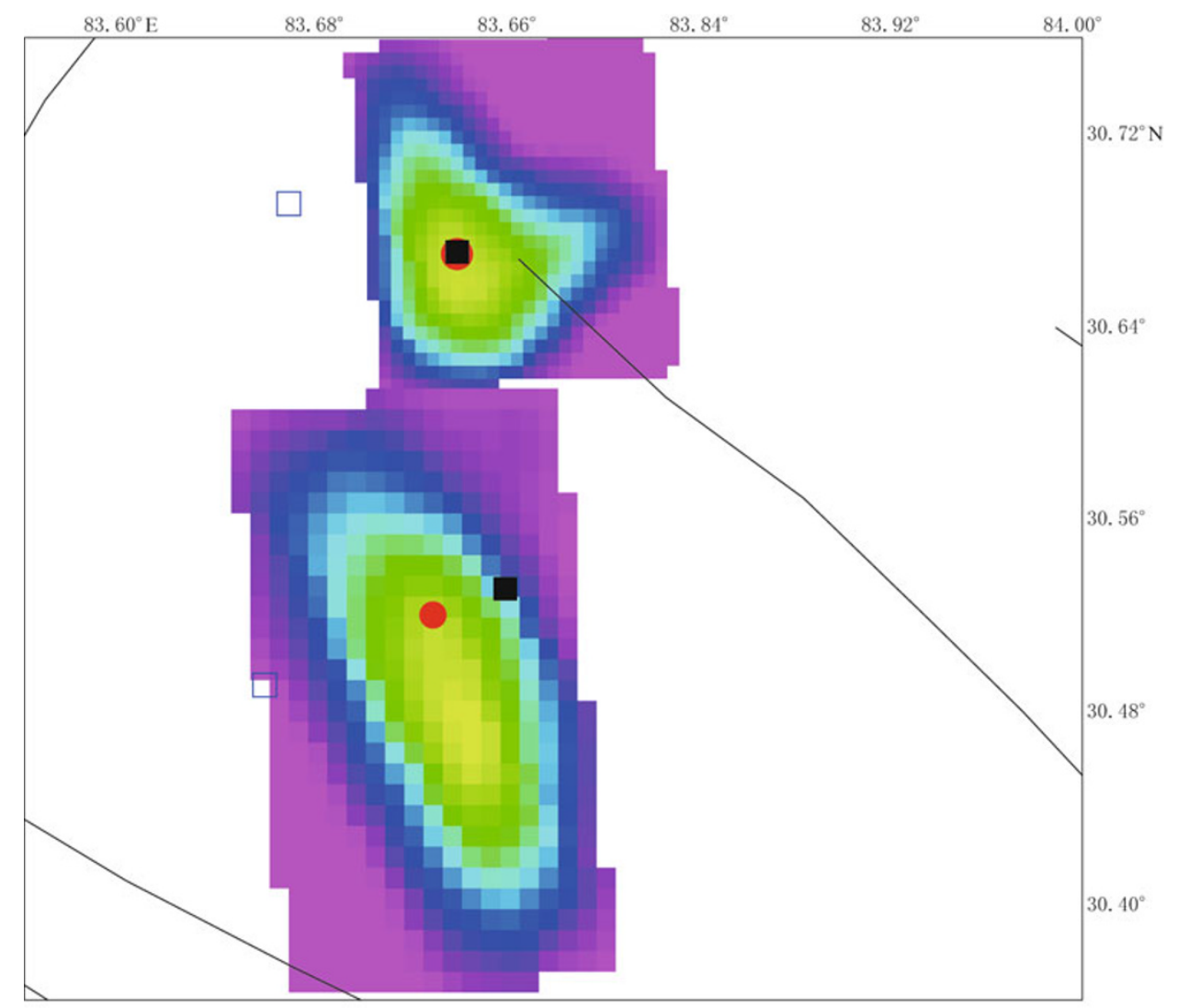

Figure 4 Earthquake doublets co-seismic deformation fields using InSAR technique. The blue open squares were earthquake doublets located by USGS, the black solid squares are located via MERL, and red dots are the centroid location from InSAR inversion. 
from SAR images recorded by the European Space Agency's (ESA) C-Band ENVISAT. We have used the interferometric pair 20040317 and 20040908 to obtain the co-seismic deformation of 11th July, 2004 main event. Correspondingly, the deformation of 7th April, 2005 mainshock has been resolved using acquisitions from the pair 20050109 and 20050529. We utilized a sensitivitybased iterative method (Wang et al., 2008) to derive the slip distribution from the InSAR data. The fault dimension of the 11th July, 2004 is $16 \mathrm{~km} \times 16 \mathrm{~km}$, in the along-strike and down-dip directions, respectively, while the fault dimension of 7th April, 2005 extends 27 $\mathrm{km}$ along-strike and $18 \mathrm{~km}$ in the down-dip direction. To solve the slip distribution that best describing the observed deformation, we have used a preliminary geometry of each fault derived from cut and paste (CAP) method as the constrained fault mechanism in the inversion process. To contradistinguish seismic results and geodetic results, the slip distribution was superimposed on the orthographic projection plane of faults at the horizontal surface (Figure 4). The two red solid circles represent the centroid points of the slip distributions. It seems that the earthquake doublets' rupture zones separate from each other and non-overlapping exist, which is similar to the result of aftershock zones. From InSAR inversion, we found that the 2004 mainshock is about 15 $\mathrm{km}$ in length and $15 \mathrm{~km}$ in width, and the 2005 even$\mathrm{t}$ is about $25 \mathrm{~km}$ in length and $15 \mathrm{~km}$ in width. And these two events' ruptures do not overlap though they are very close to each other.

\subsection{Focal depth determination}

It is difficult to determine focal depth precisely by using traditional methods. It's known that most station$\mathrm{s}$ are set up in the surface and we can easily constrain horizontal parameters such as epicenter. However, the observation of these stations has little vertical information about earthquake, so we cannot easily determine focal depth. Meanwhile, focal depth and seismic travel time has stronger dependency on the position equation and traditional location methods have difficulty to decouple them. Thus, in our research, we choose cut and paste (CAP) to determine focal depth. CAP as a full waveform inversion method, is an effective tool to locate focal depth. The 31 events of magnitude greater than 3.7 , which have been located and cataloged by USGS from 1 July 2004 to 1 July 2005, were relocated. We obtained epicenter via MERL and we gained focal depth by CAP.

As is described in the Figure 5, earthquake doublets sequences present a linear and limited distribution, they are independent of each other and do not have any overlap as an entity, neither horizontally nor vertically.
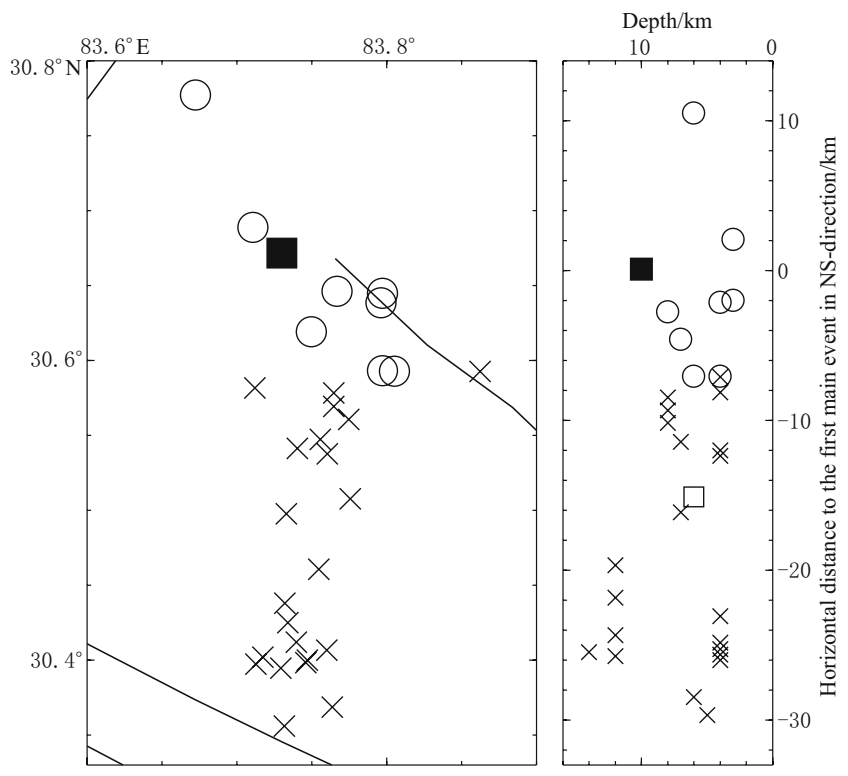

Figure 5 Location of earthquake sequences from 1 July 2004 to 1 July 2005. (a) Horizontal distribution via MERL; (b) Depth distribution via CAP from south to north of study area. Black solid squares are the master event, the first mainshock relocated by HYPOINVERSE-2000; The open square is the second mainshock's location, 7 April 2005. Circles are the aftershock sequences of magnitude 3.7 or greater from 1 July 2004 to 6 April 2005 . And Crosses are the aftershock sequences of magnitude 3.7 or greater from 7 April 2005 to 1 July 2005.

\section{Discussion and conclusions}

In this study the MERL technique has been applied to studying aftershocks of earthquake doublets, July 112004 and April 7 2005, in south-central Tibet from $30^{\circ} \mathrm{N}$ to $31^{\circ} \mathrm{N}$ and $83^{\circ} \mathrm{E}$ to $84^{\circ} \mathrm{E}$, to obtain clearer views of aftershock zones and seismicity distribution then study characteristic of two rupture zones. It is demonstrated that the relative location method presented in this study indicates a significant improvement in location precision in the existing preliminary locations determined by the routine earthquake location method and listed in the NEIC's catalog due to the reduction of errors in structure. Meanwhile, we also modeled two mainshocks with INSAR data and studied earthquake doublets' co-seismic rupture zones.

The two M6 mainshocks are very close to each other according to NEIC's catalog, and their aftershocks 
look like to overlap each other, which may suggest that the earthquake doublets ruptured and produced an overlapped area, however, this study find that epicenters of aftershocks for the earthquake doublets can be distinguished from each other, which means that rup- ture zones of the two mainquakes were not overlapping basically. Earthquake doublets' co-seismic deformation fields have been obtained by InSAR technique, which also confirms that these two co-seismic ruptures are not overlapping (Figure 6).

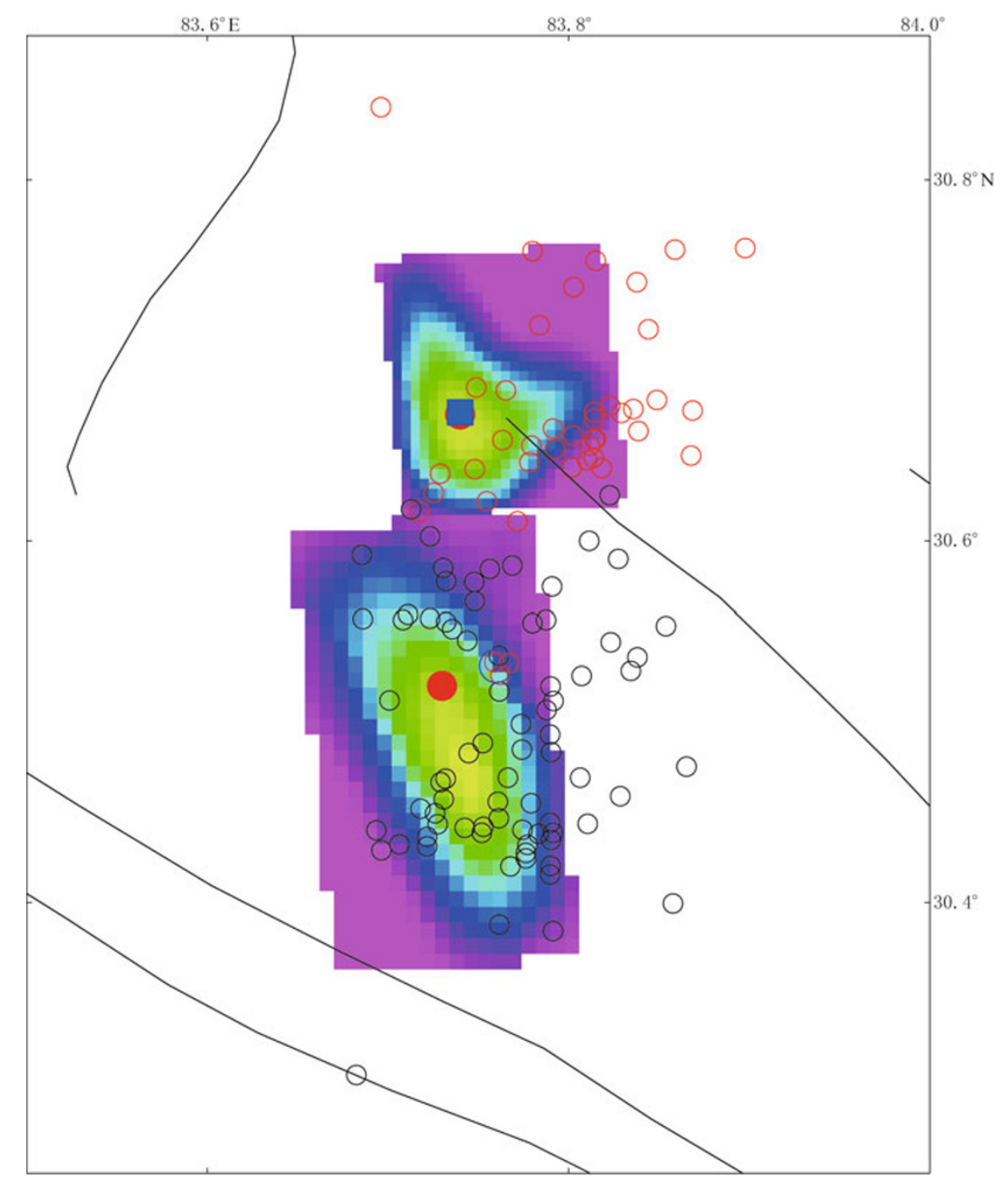

Figure 6 Superposition of earthquake doublets' rupture zones through two methods. Two blue solid squares are mainshocks relocated by HYPOINVERSE-2000. The red open stars are the aftershock sequences within a week after the first mainshock, 11 July 2004. And the black open stars are the aftershock sequences within a week after the second mainshock, 7 April 2005. The red solid circles are the centroid location from InSAR inversion.

It has been discovered that widely distributed NS trending rifts or rift-depressions and NE and NW trending strike-slip faults have been developed in southern Tibet. And in this area, the north-south trending normal faults, north-east and north-west trending strikeslip faults are the major active tectonics (Wang et al., 2000). In this study, the epicenters of earthquake dou- blets are mainly located at the intersections of northsouth and north-west fracture, and two rupture zones from seismological and InSAR methods present nearly NS-trending distribution, which is parallel to the NStrending rifts' direction. It can be conjectured that the earthquake doublets maybe influenced by north-south fracture zones. 
The expansion of the aftershock area with time has been noted for many earthquakes, and it is considered that if a short time period after the main earthquake is selected, the aftershock area gives a good estimate of the co-seismic rupture zone of the mainshock (Henry and Das, 2001; Bao et al., submitted for publication). Furthermore, structural features of fault zones might be related to the sizes and locations of early aftershock zones, which could be the result of stress rearrangement after mainshocks and mainly distributed along the rupture zones (Mendoza and Hartzell, 1988). In addition, some aftershock, happening in some distance from the mainshock possibly, might be triggered by the mainshock statically. In this study, the rupture zones of the earthquake doublets, described as early aftershock zones, were accommodated by discrete segments rather than overlap for reasonable short periods, just within a seismogenic period.

Acknowledgements All the people involved in the servicing of the Hi-CLIMB network and those who prepared the data set should find here our furthest acknowledgement. Thanks to Dr. Wessel P and Dr. Smith W H F for providing us with the software GMT (the Generic Mapping Tools). And thanks to the researchers of LLNI (Lawrence Livermore National Laboratory, University of California) for providing us with the software SAC (Seismic Analysis Code). This study is supported jointly by Joint Seismological Science Foundation of China (Nos.200808078 and 200708035).

\section{References}

Aki K (1978). Origin of the seismic gap: What initiates and stops a rupture propagation along a plate boundary? US Geol Surv Open-file Rep: 78-943.

Aki K (1979). Characterization of barriers on an earthquake fault. J Geophys Res 84: 6 140-6 148.

Bao F, Ni S, Wang Z, Wang W, Wen X and Liu Q. Overlapping degree of 2003 Dayao two strong earthquakes' rupture zones. Acta Seismologica Sinica, Submitted (in Chinese with English abstract).

Fedotov S A (1965). Regularities of the distribution of strong earthquakes in Kamchatka, the Kuril Islands, and northeastern Japan. Trudy Inst Fiz Zemli 36(203): 66-93 (in Russian).

Henry C and Das S (2001). Aftershock zones of large shallow earthquakes: Fault dimensions, aftershock area expansion, and scaling relations. Geophys J Int 147: 272-293.

Hetenyi G, Vergne J, Nabelek J, Cattin R, Brunet F, Bollinger L and Diament M (2008). Structure of the crust and the lithosphere in the Himalaya-Tibet region and implications on the rheology and eclogitization of the India plate. Himalayan Journal of Sciences 5(7): 65-66.

Kelleher J A (1970). Space-time seismicity of the AlaskaAleutian seismic zone. J Geophys Res 75: 5 745-5 756.

Li J, Wang W M, Zhao L F and Yao Z X (2005). Rupture process of the July 11, 2004, Tibet ( $\left.M_{\mathrm{W}} 6.2\right)$ earthquake. Chinese J Geophys 48(4): 843-850 (in Chinese with English abstract).

Kisslinger C (1996). Aftershocks and fault-zone properties. Adv Geophys 38: 1-36.

Massonnet D, Feigl K, Rossi M and Adragna F (1994). Radar interferometric mapping of deformation in the year after the landers earthquake. Nature 369: 227-230.

Mendoza C and Hartzell S H (1988). Aftershock patterns and main shock faulting. Bull Seismol Soc Am 78(4): 1438-14 49.

Mogi K (1969). Some features of recent seismic activity in and near Japan (2). Bull Earthq Res Inst, Univ Tokyo 47: $395-417$.

Nabelek J, Hetenyi G, Vergne J, Sapkota S, Kafle B, Jiang M, Su H P, Chen J and Huang B S (2009). Underplating in the Himalaya-Tibet collision zone revealed by the Hi-CLIMB experiment. Science 325: 1371.

Saikia C K, Lohman R, Ichinose G and Simons M (2003). Ground truth locations using a synergy between INSAR and seismic methods. In: Proc. 25th Seism. Res. Rev.. Ponte Vedra Beach, Florida, 1: 324-333.

Segall P and Pollard D D (1980). Mechanics of discontinuous faults. J Geophys Res 85: 4337-4 350.

Somerville P, Sen M and Cohee B (1991). Simulations of strong ground motions recorded during the $1985 \mathrm{Mi}-$ choacan, Mexico and Valparaiso, Chile earthquakes. Bull Seismol Soc Am 81(1): 1-27.

Sykes L R (1971). Aftershock zones of great earthquakes, seismicity gaps, and earthquake prediction for Alaska and the Aleutians. J Geophys Res 79: 8021.

Spence W (1980). Relative epicenter determination using P-wave arrival-time differences. Bull Seismol Soc Am 70(1): 171-183.

Waldhauser F and Ellsworth W L (2000). A doubledifference earthquake location algorithm: Method and application to the northern Hayward fault, California. Bull Seismol Soc Am 90(6): 1353-1368.

Wan K, Ni S, Zeng X and Paul S (2009). Real-time seismology for the 05/12/2008 Wenchuan earthquake of China: A retrospective view. Science in China (series D) 52(2): 155-165.

Wang Y, Li Q, Wan J and Li D (2000). Formation and dynamic analysis of NS trending structure in southern Tibet. Seismology and Geology 22(Suppl.): 117-124 (in Chinese with English abstract).

Wang R, Motagh M and Walter T R (2008). Inversion of slip distribution from co-seismic deformation data by a sensitivity-base iterative fitting method. EGU General Assembly 2008, EGU2008-A-07971. 
Wittlinger G, Farra V, Hetenyi G, Vergne J and Nabelek J (2009). Seismic velocities in Southern Tibet lower crust: A receiver function approach for eclogite detection. Geophys J Int 177: 1037-1049.

Xu X W, Wen X Z, Ye J Q, Ma B Q, Chen J, Zhou R J, He H L, Tian Q J, He Y L, Wang Z C, Sun Z M, Feng X J, Yu G H, Chen L C, Chen G H, Yu S E, Ran Y K, Li X G, Li C X, and An Y F (2008). The $M_{\mathrm{S}} 8.0$ Wenchuan earthquake surface ruptures and its seismogenic structure. Seismology and Geology 30(3): 597-629 (in Chinese with English abstract).

Xu X L and Li F (2008). Extracting coseismic deformation of the 2004 Zhongba earthquake with InSAR and D-InSAR. Science of Surveying and Mapping 33(3): 19-21 (in Chinese with English abstract).

Yang Z X, Chen Y T and Zhang H Z (2002). Relocation and seismogenic structure of the 1998 Zhangbei-Shangyi earthquake sequence. Acta Seismologica Sinica 15(4): 383-394.

Zhao L S, Helmberger D V and Harkrider D G (1991). Shearvelocity structure of the crust and upper mantle beneath the Tibetan Plateau and southeastern China. Geophy J Int 105(3): 713-730.

Zhao W, Mechie J, Brown L D, Guo J, Haines S, Hearn T, Klemperer S L, Ma Y S, Meissner R, Nelson K D, Ni J F, Pananont P, Rapine R, Ross A and Saul J (2001). Crustal structure of central Tibet as derived from project INDEPTH wide-angle seismic data. Geophy $J$ Int 145: 486-498.

Zhou S, Xu Z, Han J, Xu H and Nuernisha (1999). Analysis on the master event method and precise location of 1997 Jiashi strong earthquake swarm in western China. Acta Seismologica Sinica 12(3): 285-291. 